Article

\title{
Light-Induced Reactions of Chlorpromazine in the Presence of a Heterogeneous Photocatalyst: Formation of a Long-Lasting Sulfoxide
}

\author{
Arsou Arimi ${ }^{1, *(\mathbb{C})}$, Ralf Dillert ${ }^{1,2, * \mathbb{C}}$, Gerald Dräger ${ }^{3}{ }^{(\mathbb{C}}$ and Detlef W. Bahnemann ${ }^{1,2,4, *(\mathbb{C})}$ \\ 1 Institut für Technische Chemie, Gottfried Wilhelm Leibniz Universität Hannover, Callinstrasse 3, \\ D-30167 Hannover, Germany \\ 2 Laboratorium für Nano- und Quantenengineering, Gottfried Wilhelm Leibniz Universität Hannover, \\ Schneiderberg 39, 30167 Hannover, Germany \\ 3 Institut für Organische Chemie, Gottfried Wilhelm Leibniz Universität Hannover, Schneiderberg 1B, \\ D-30167, Hannover, Germany \\ 4 Laboratory "Photoactive Nanocomposite Materials", Saint-Petersburg State University, Ulyanovskaya str.1, \\ Peterhof, Saint-Petersburg 198504, Russia \\ * Correspondence: arimi@iftc.uni-hannover.de (A.A.); dillert@iftc.uni-hannover.de (R.D.); \\ bahnemann@iftc.uni-hannover.de (D.W.B.); Tel.: +49(0)511-762-2773 (A.A.); +49(0)511-762-16039 (R.D.); \\ +49(0)511-762-5560 (D.W.B.)
}

Received: 1 July 2019; Accepted: 17 July 2019; Published: 22 July 2019

\begin{abstract}
A commercial carbon-modified titanium dioxide, KRONOClean 7000, was applied as a UV(A) and visible-light active photocatalyst to investigate the conversion of the antipsychotic pharmaceutical chlorpromazine in aqueous phase employing two monochromatic light sources emitting at wavelengths of 365 and $455 \mathrm{~nm}$. Photocatalytic and photolytic conversion of chlorpromazine under both anaerobic and aerobic conditions was analyzed using a HPLC-MS technique. Depending on the irradiation wavelength and presence of oxygen, varying conversion rates and intermediates revealing different reaction pathways were observed. Upon visible light irradiation under aerobic conditions, chlorpromazine was only converted in the presence of the photocatalyst. No photocatalytic conversion of this compound under anaerobic conditions upon visible light irradiation was observed. Upon UV(A) irradiation, chlorpromazine was successfully converted into its metabolites in both presence and absence of the photocatalyst. Most importantly, chlorpromazine sulfoxide, a very persistent metabolite of chlorpromazine, was produced throughout the photolytic and photocatalytic conversions of chlorpromazine under aerobic conditions. Chlorpromazine sulfoxide was found to be highly stable under visible light irradiation even in the presence of the photocatalyst. Heterogeneous photocatalysis under UV(A) irradiation resulted in a slow decrease of the sulfoxide concentration, however, the required irradiation time for its complete removal was found to be much longer compared to the removal of chlorpromazine at the same initial concentration.
\end{abstract}

Keywords: chlorpromazine; chlorpromazine sulfoxide; KRONOClean 7000; visible light-driven photocatalysis; HPLC-MS

\section{Introduction}

The presence of pharmaceutical residues is being reported globally in water and wastewater streams during the past few decades and this issue has become a big concern [1]. As many of these medicinal compounds are essential in remedial applications for human/animal health, their consumption cannot be minimized or limited [2,3]. Despite the very low concentrations of these chemicals in aquatic systems, they result in serious problems in the environment for humans and 
for living organisms, since they are designed in a way to have specific physiological effects on living organisms [4-6]. Generally, these chemicals have structures which cannot be biologically degraded by conventional treatment methods $[7,8]$ and therefore, some post-treatment steps are additionally required for their proper removal [9-11]. Nevertheless, these methods might not be adequate to remove the large variety of organic compounds present in wastewater. Thus, the effluents of conventional treatment plants are major sources of chemical discharges into the aquatic system [12].

One of the proposed methods to treat pharmaceutical-rich aquatic streams is the application of heterogeneous photocatalytic reactions $[13,14]$. Through this method, the structure of the drugs present in water and wastewater streams will be decomposed, and as a result, their negative effects on the environment, especially their toxicity, will be reduced [15]. Recently, solar light driven heterogeneous photocatalysis in the treatment of contaminated wastewater has been widely investigated [16-21]. $\mathrm{TiO}_{2}$ is the most commonly used photocatalyst in heterogeneous photocatalytic processes. However, despite its high stability, low toxicity, and low cost, this photocatalyst is not able to absorb the sunlight efficiently. Only $5 \%$ of sunlight can be absorbed by bare $\mathrm{TiO}_{2}$ and the visible part of the solar energy remains unutilized [22]. Thus, having a visible-light active photocatalyst allows effectively harvesting and utilizing the solar energy in wastewater treatment.

In order to increase the light absorption by $\mathrm{TiO}_{2}$, some methods have been investigated such as doping with metal ions or adsorption of compounds acting as sensitizers on the surface of the photocatalyst. By doping the $\mathrm{TiO}_{2}$ surface with metal ions, the absorption of this photocatalyst will be altered to higher wavelengths leading to its increased visible light absorption [23-26]. The latter approach using dyes as a sensitizer is commonly used in dye sensitized solar cells [27,28] as well as in photocatalytic applications [29-32]. However, due to the adsorption of the dye on the photocatalyst surface, the absorption spectrum of the photocatalyst will be changed [33]. This by-effect can be avoided when applying a carbon-based layer on the surface of the photocatalyst as applied for KRONOClean 7000, the commercially available carbon-modified $\mathrm{TiO}_{2}$, also known as VLP or Kronos VLP 7000 in the literature [34-36]. KRONOClean 7000 (named in this work as K-7000) is a commercial carbon-modified $\mathrm{TiO}_{2}$ with no pigmentary properties, produced by Kronos International, Inc. K-7000 is one of the commercially available UV light active photocatalysts which also shows a high activity in response to visible light. This material is an ultra-fine carbon modified titanium dioxide with anatase crystal modification in which due to an aromatic carbon-based sensitizer layer, the visible light can be absorbed [35]. K-7000 is a bimodal anatase that is able to decompose organic pollutants as well as odors and NOx compounds [34,35]. As reported by the producer, this material has a BET surface area of $225 \mathrm{~m}^{2} \mathrm{~g}^{-1}$ and an average crystallite size of about $15 \mathrm{~nm}$ [37]. Detailed characteristic and morphological studies on this photocatalyst have been reported before [34-36]. Zabek et al. have shown that by this modification the bandgap position of the photocatalyst did not change (compared to bare anatase $\mathrm{TiO}_{2}$ ) while the visible light absorption was increased [35]. K-7000 has shown a stable photocatalytic activity after three consecutive experimental runs which confirmed its reusability for visible light-driven photocatalytic applications [36]. Furthermore, the photo-stability of the sensitizer layer on the $\mathrm{TiO}_{2}$ upon visible irradiation was also proved through eighteen hours of photo-mineralization of 4-chlorophenol [35].

Antipsychotic drugs are frequently detected among the various categories of pharmaceuticals contaminating the water system. These drugs are used widely around the world, while their increased consumption leads to the enhanced release of these compounds and their metabolites into the environment [38]. One of the most commonly prescribed groups of psychotropic drugs in the world is called the phenothiazine group [39,40]. Phenothiazine drugs might end up in water or wastewater streams after their consumption, in the sewage treatment plant effluents, or as effluents of the pharmaceutical companies [41,42]. Residual traces of these drugs or their transformation products in aquatic environments with possible ecotoxicological properties have already been detected and reported $[41,43,44]$. Generally, the oxidation process of phenothiazines leads to one, two, 
or four-electron oxidation products and the two-electron oxidation product is reported to be the sulfoxide metabolite [45].

Chlorpromazine hydrochloride, [3-(2-chloro-10H-phenothiazin-10-yl) propyl] dimethylamine hydrochloride, the most popular compound from the phenothiazine group, is one of the first of its kind which was released to the pharmaceutical market in 1952 [46]. This compound is photosensitive in liquid or solid form and its negative effects upon exposure to sunlight in the human body are already identified [47]. The dechlorinated free radicals produced from irradiation of this compound in the body react with the DNA and form singlet oxygen [48]. The formation of short-lived radicals causing genotoxic consequences was indicated as well [49]. Chlorpromazine is known to be converted into its metabolites upon UV irradiation through demethylation in the N-chain, oxidation of sulfur or nitrogen, or ring hydroxylation $[43,50]$. Chlorpromazine absorbs light more strongly at wavelengths shorter than $300 \mathrm{~nm}$ and the resulting excited singlet state easily converts into the triplet state. The excited states either fragment to form radicals or photo-ionize to form radical cations and electrons [51]. The main metabolite in photolytic transformation of chlorpromazine, namely, chlorpromazine sulfoxide (named in this work as SFX) is obtained by the direct reaction of chlorpromazine with molecular oxygen [52]. It is also likely to be produced through hydrolysis of the radical cation [53]. Trautwein and Kümmerer investigated the fate of chlorpromazine and its potential transformation through aerobic and anaerobic biodegradation as well as abiotic photolytic degradation by sunlight. They observed nearly complete elimination of chlorpromazine within $4 \mathrm{~h}$ of illumination by a xenon arc lamp. They determined the molecular structures of the three main photolysis products having $\mathrm{m} / \mathrm{z}$ values of 301,317 , and 335, through an analysis by high performance liquid chromatography coupled to multiple stage mass-spectrometry (HPLC-MS ${ }^{n}$ [ [43]. In another study, Kigondu et al. evaluated the antimycobacterial activities of chlorpromazine and its metabolites alone and in combination with antitubercular drugs in which intermediates with $\mathrm{m} / \mathrm{z}$ values of 335 and 351 were detected [54]. These compounds were also reported in an analytical study by Boehme and Strobel in which two HPLC methods have been introduced to analyze the in vitro metabolism of chlorpromazine [55].

On the other hand, chlorpromazine was reported to show diverse behaviors upon UV irradiation under aerobic and anaerobic conditions. The photo-induced reaction of chlorpromazine under anaerobic conditions revealed that polymerization and dimerization processes predominated upon anaerobic UV photolysis and, interestingly, no evidence of the formation of SFX or other photolytic products of the aerobic conditions was observed. It was suggested that the free radical cations of chlorpromazine resulted from cleavage of chloride function from the structure, promotion of these processes and the polymers were found to be the major products [56].

Despite the extended studies on photolytic degradation of chlorpromazine in aqueous solutions, to the best of the authors' knowledge, very little is known about the photocatalytic conversion of this compound and its metabolites in aqueous systems and their possible removal from water streams. The photocatalytic conversion of chlorpromazine (in a mixture with two other pharmaceuticals) using immobilized $\mathrm{TiO}_{2}$ nanoparticles (PC-500) upon UV irradiation was investigated by Khataee et al. [57]. They have reported 90\% removal of chlorpromazine in the mixture after 150 min UV irradiation. However, a detailed mechanistic study was not presented by these authors.

In the current study, photocatalytic and photolytic conversions of chlorpromazine using K-7000 photocatalyst upon UV(A) and visible light irradiation at both anaerobic and aerobic conditions were studied. Furthermore, the photocatalytic and photolytic transformations of the highly stable metabolite, SFX, produced under aerobic conditions throughout a long-term irradiation period and its stability over this process were analyzed.

\section{Results and Discussion}

In the current study, the conversion of chlorpromazine under photocatalytic conditions as well as photolytic conditions upon both UV(A) $(365 \mathrm{~nm})$ and visible $(455 \mathrm{~nm})$ light irradiation was investigated. KronoClean 7000 (K-7000) was applied as a photocatalyst for conversion of chlorpromazine using 
UV(A) and visible light sources. The experimental runs were performed in the presence and absence of molecular oxygen at room temperature and natural $\mathrm{pH}$ of the suspension. Accordingly, the reaction intermediates at both photocatalytic and photolytic processes were detected and compared to figure out the possible reaction pathway for the photocatalytic reaction.

\subsection{Photocatalytic and Photolytic Conversion of Chlorpromazine}

The photocatalytic and photolytic conversions $\left(\mathrm{C} / \mathrm{C}_{0, \mathrm{e}}\right)$ of the probe compound (chlorpromazine) versus reaction time upon $\mathrm{UV}(\mathrm{A})$ and visible light irradiation at, respectively, 365 and $455 \mathrm{~nm}$ wavelengths using K-7000 as photocatalyst in aerobic conditions are presented in Figure 1. These experimental runs were performed for $180 \mathrm{~min}$, however, in the following graph, only the first 60 min of irradiation are presented.

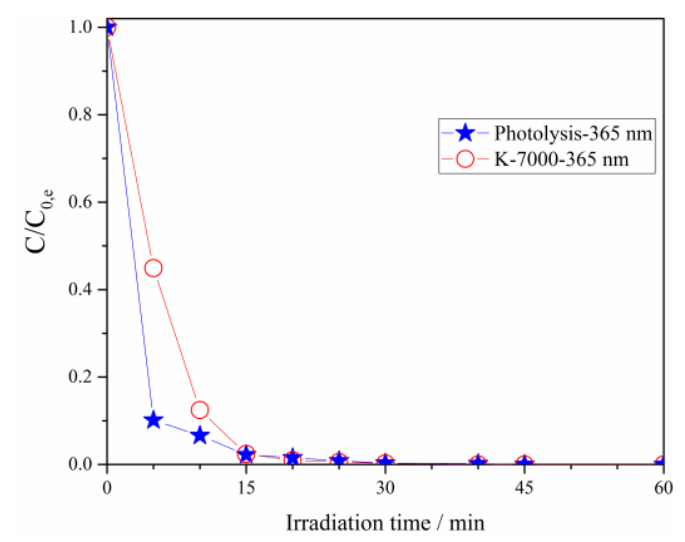

(a)

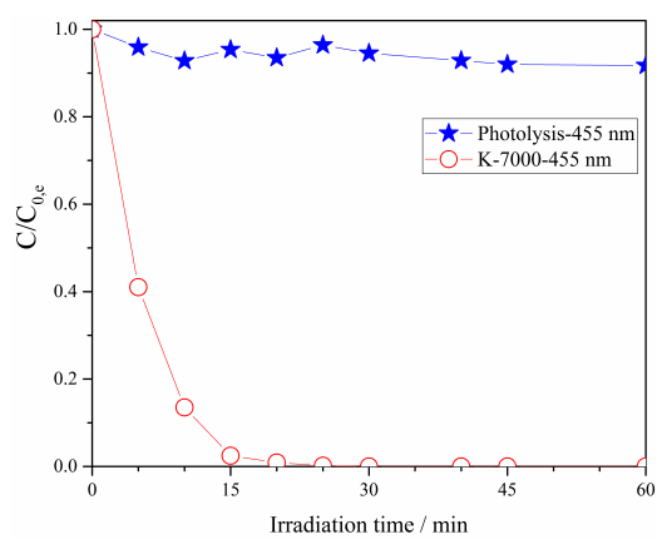

(b)

Figure 1. Photocatalytic and photolytic conversions of chlorpromazine upon (a) UV(A) and (b) visible light irradiation $\left(\mathrm{C}_{0}: 100 \mu \mathrm{M}\right.$-Catalyst: $\mathrm{K}-7000\left(1 \mathrm{~g} \mathrm{~L}^{-1}\right)$-Irradiation wavelengths: 365 and $\left.455 \mathrm{~nm}\right)$.

As can be seen in Figure 1, in the presence of K-7000 as photocatalyst upon both UV(A) and visible light irradiation, up to $90 \%$ of the chlorpromazine initially present in the aqueous phase was converted after only $10 \mathrm{~min}$ of irradiation and almost complete conversion was achieved within 30 min of irradiation. Upon UV(A) irradiation however, the photocatalytic reaction seems to be slower than the photolytic reaction. This suggests that during the photocatalytic reaction under UV(A) irradiation, most of the photons are absorbed by the photocatalyst itself; therefore, the contribution of the homogeneous reaction (photolytic excitation of the probe compound) is small compared to the photocatalytic reaction.

In comparison, in the photolytic procedure, after $30 \mathrm{~min}$ of irradiation with $455 \mathrm{~nm}$ wavelengths, only a slight decrease (5\%) in the chlorpromazine concentration was observed (Figure $1 \mathrm{~b}$ ) indicating the high stability of this compound upon visible light irradiation. Nevertheless, after $30 \mathrm{~min}$ of UV(A) irradiation, up to $99 \%$ of the pharmaceutical was converted photolytically. It becomes obvious from Figure 2 that the absorbance of chlorpromazine at $365 \mathrm{~nm}$ is significantly larger than at $455 \mathrm{~nm}$. Consequently, less amount of photons are absorbed at $455 \mathrm{~nm}$. Due to this low absorption, a significant part of photons will be lost by transmission through the suspension resulting in a weak photolysis of chlorpromazine at this wavelength. 


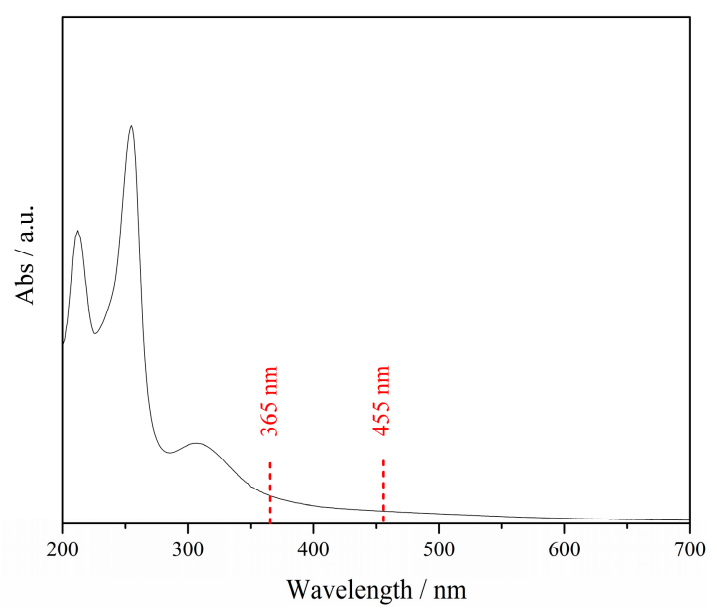

Figure 2. Absorption spectrum of a $100 \mu \mathrm{M}$ chlorpromazine solution in water.

All the photocatalytic and photolytic experiments followed a first order kinetic behavior; except for photolysis upon visible light irradiation $(455 \mathrm{~nm})$ in which the conversion of the probe compound was negligible (5\%). The rate constant values for UV(A)-photocatalysis, visible light-photocatalysis, and UV(A)-photolysis were calculated to be $0.21 \pm 0.01,0.24 \pm 0.01$, and $0.19 \pm 0.01$, respectively. At first glance, no significant difference in the conversion rates of the photocatalytic reactions upon UV(A) and visible light irradiations is observed. However, the photon flux density, N, emitted by the UV(A) and the Visible light LED lamps were calculated to be $1.12 \times 10^{16} \mathrm{~s}^{-1} \mathrm{~cm}^{-2}$ and $7.47 \times 10^{16} \mathrm{~s}^{-1} \mathrm{~cm}^{-2}$, respectively. This reveals that under identical experimental conditions, the amount of emitted photons from the visible light LED lamp was almost seven times higher compared to that of the UV(A) LED lamp. Therefore, even though the rate constant of the photocatalytic process seems to be a bit higher upon visible light irradiation, considering the much higher photon flux density of the visible light lamp, K-7000 was found to be less active upon visible light irradiation than upon UV(A) irradiation.

During the photolysis upon visible light irradiation, the chlorpromazine suspension reached a strong pink color after $5 \mathrm{~min}$ and it turned colorless after $15 \mathrm{~min}$ of irradiation. However, throughout the photolytic experiment upon UV(A) irradiation, the colorless suspension of chlorpromazine turned to pink and ruby. Nevertheless, no change of color was observed during the photocatalytic experiments in the presence of K-7000. From these observations, a possible variety of intermediates throughout different reaction pathways seems to be likely.

Accordingly, some intermediates produced during the experimental runs were detected via HPLC-MS analysis. These compounds are named in this manuscript according to their detected molecular mass (or $\mathrm{m} / \mathrm{z}$ value). The photocatalytic and photolytic transformation of chlorpromazine (m/z: 319) resulted in the formation of products having $\mathrm{m} / \mathrm{z}$ values of $301,317,335$, and 351 . Figure 3 demonstrates the time course of the products/intermediates formation during the photocatalytic and photolytic conversion of chlorpromazine upon both UV(A) and visible light irradiation. The main conversion products found during the first $60 \mathrm{~min}$ of the photocatalytic experimental runs upon UV(A) irradiation have $\mathrm{m} / \mathrm{z}$ values of 335,351 , and 317 (Figure 3a); however, for the photocatalytic process upon visible light irradiation, only the intermediates with $\mathrm{m} / \mathrm{z}$ values of 335 and 351 were detected (Figure $3 b)$. Interestingly, throughout the photocatalytic reaction upon both UV(A) and visible light irradiation, the intermediate giving the highest signal intensity $(\mathrm{m} / \mathrm{z}=335)$ was found to be highly stable over the reaction period. 


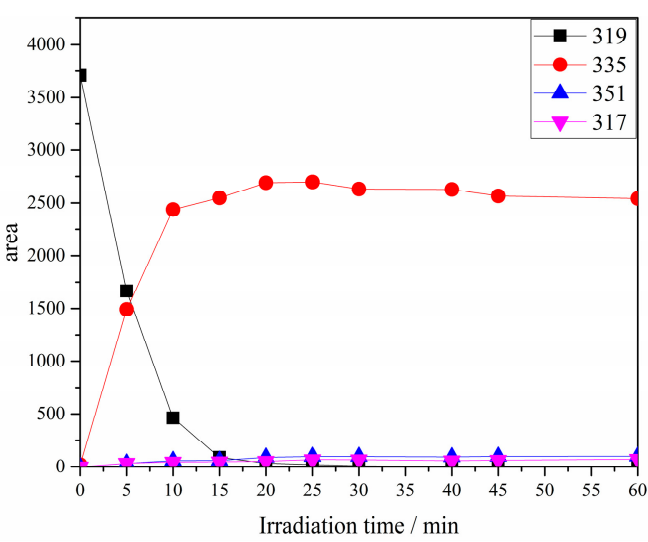

(a)

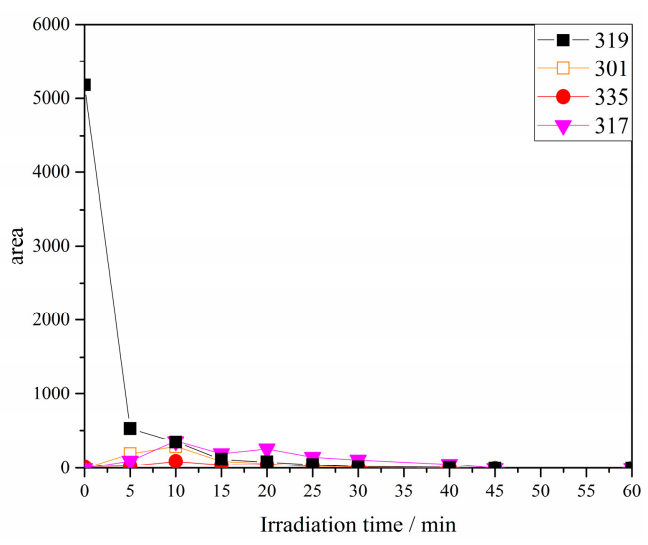

(c)

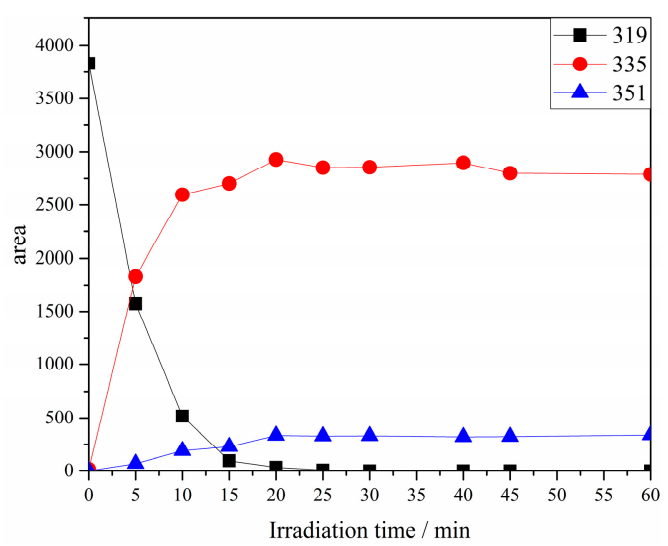

(b)

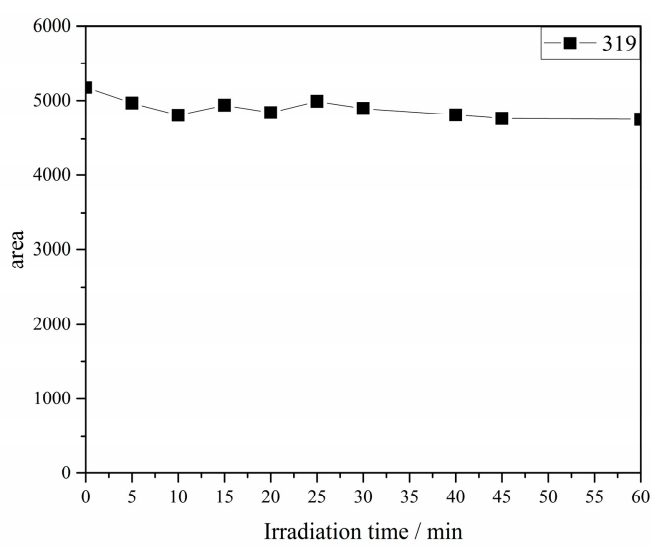

(d)

Figure 3. Time course of the intermediates formation during chlorpromazine conversion: (a) photocatalysis upon UV(A) irradiation, (b) photocatalysis upon visible light irradiation (K-7000 as photocatalyst $\left.\left(1 \mathrm{~g} \mathrm{~L}^{-1}\right)\right)$, (c) photolysis upon $\mathrm{UV}(\mathrm{A})$ irradiation, and (d) photolysis upon visible light irradiation.

Alternatively, during the photolytic reaction upon UV(A) irradiation (Figure 3c), compounds with $\mathrm{m} / \mathrm{z}$ values of 301,335 , and 317 were observed and no intermediates for the photolytic reaction upon visible light irradiation (Figure 3d) were detected as the conversion of the probe compound was negligible.

As revealed by the intermediates analysis, conversion rate of the probe compound as well as type and production rates of the intermediates varied upon $\mathrm{UV}(\mathrm{A})$ and visible light irradiation in presence and absence of the photocatalyst. Three main detected products in photolysis upon UV(A) irradiation, having $\mathrm{m} / \mathrm{z}$ values of 335,317 , and 301 were also reported for this reaction in similar analytical studies and for each of these compounds, one or more possible structures have been proposed [43,44,54,55]. Some of the intermediates with significant signal intensities detected throughout the photocatalytic and photolytic conversion of chlorpromazine under aerobic conditions, their retention times, masses, and reported structures are gathered in Table 1. 
Table 1. Chlorpromazine and some of the reaction intermediates of its photocatalytic and photolytic conversion under aerobic conditions, their retention times, masses, and possible structures.

\begin{tabular}{|c|c|c|}
\hline Retention Time/min & Mass (m/z) & Possible Structures (Found as $[\mathrm{M}+\mathrm{H}]^{+}$) \\
\hline 19.2 & 319 & \\
\hline 15.8 & 301 & \\
\hline 11.7 & 317 & \\
\hline 14.7 & 335 & \\
\hline 15.2 & 351 & \\
\hline
\end{tabular}

The molecular mass of the highly persistent intermediate giving the highest signal intensity with $\mathrm{m} / \mathrm{z}$ value of 335 corresponds either to chlorpromazine sulfoxide (SFX) or to chlorpromazine -N-oxide [54]. Therefore, in order to identify this produced metabolite, a pure commercial SFX was analyzed by HPLC-MS and the obtained signal for the commercial SFX matched $100 \%$ to that of the metabolite with $\mathrm{m} / \mathrm{z}$ value of 335 in the experimental runs, confirming the identity of the produced metabolite to be the SFX.

\subsection{Long Term Experiments with Chlorpromazine Sulfoxide}

Chlorpromazine sulfoxide (SFX) was found to be a highly stable product of the photocatalytic conversion of chlorpromazine under aerobic conditions. Therefore, the stability and transformation of this compound was investigated in long-term experiments. The experimental runs were performed under aerobic photocatalytic and photolytic conditions upon UV(A) and visible light irradiation (Figure 4). 


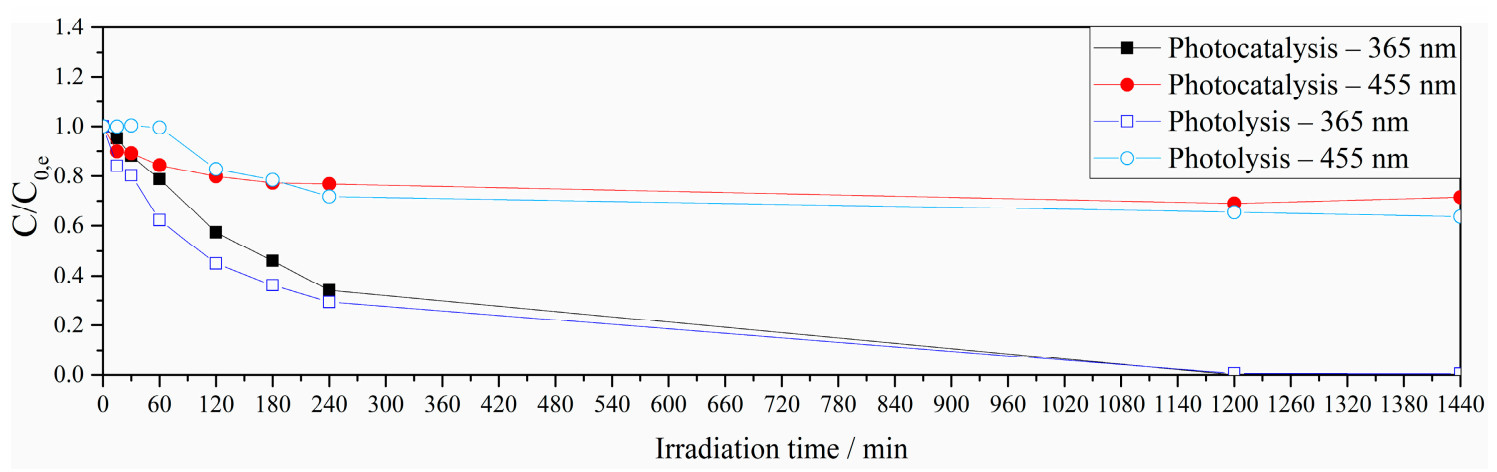

Figure 4. Long term photocatalytic and photolytic conversion of chlorpromazine sulfoxide (SFX) (100 $\mu \mathrm{M})$ upon $\mathrm{UV}(\mathrm{A})$ and visible light irradiation using K-7000 as photocatalyst $\left(1 \mathrm{~g} \mathrm{~L}^{-1}\right)$.

The long term photocatalytic experiments upon visible light irradiation revealed that SFX was converted only up to $20 \%$ during the first $2 \mathrm{~h}$ of irradiation; nevertheless, after this period it was highly stable even over the $24 \mathrm{~h}$ visible light irradiation (only $7 \%$ decrease). On the other hand, during the photocatalytic reaction upon UV(A) irradiation, SFX concentration was slowly reduced. However, the required irradiation time for its complete removal compared to the removal of chlorpromazine having the same initial concentration was found to be at least 20 times longer.

Furthermore, during the photolytic experiments upon visible light irradiation, SFX concentration decreased only up to $17 \%$ from $2 \mathrm{~h}$ to $24 \mathrm{~h}$ confirming the high stability of SFX upon visible light photolysis. However, SFX concentration was found to be slowly reduced under photolytic conditions upon $\mathrm{UV}(\mathrm{A})$ light irradiation.

Nevertheless, it seemed that upon UV(A) irradiation, the presence of the photocatalyst inhibited the conversion reaction and that the photolytic reaction was faster than the photocatalytic one. Thus, possible differences in the conversion pathways are assumed. Accordingly, the intermediates of the photocatalytic and the photolytic reactions of SFX after $2 \mathrm{~h}$ and $24 \mathrm{~h}$ of UV(A) irradiation (Figure 5) were analyzed and compared.

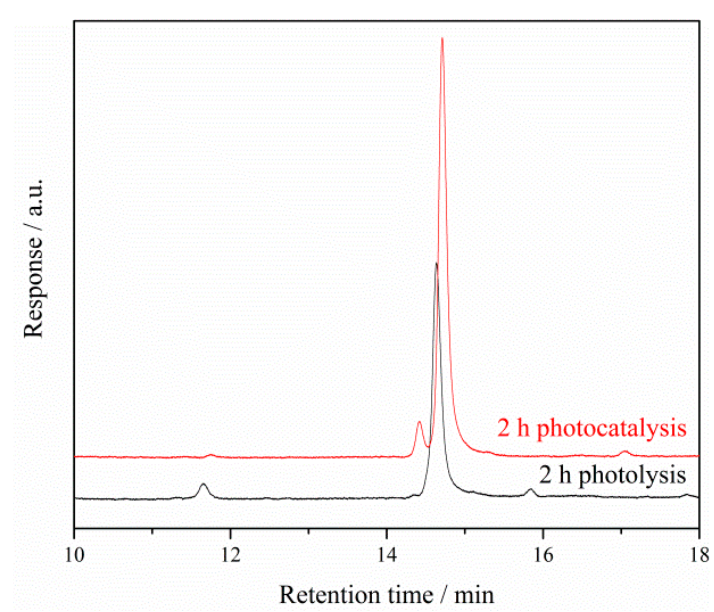

(a)

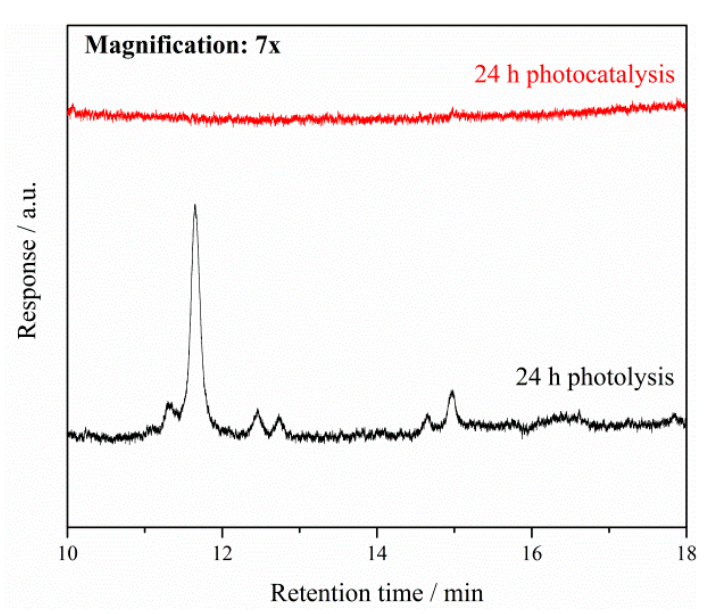

(b)

Figure 5. Chromatograms of SFX under both photocatalytic and photolytic conditions upon irradiation with UV(A) light after: (a) $2 \mathrm{~h}$ and (b) $24 \mathrm{~h}$.

Upon long term UV(A) irradiation, as assumed some differences between the photocatalytic and photolytic conversion pathways of SFX were observed. It was found that the product/intermediate distributions of these two reactions after $2 \mathrm{~h}$ and $24 \mathrm{~h} \mathrm{UV(A)}$ irradiation were different (Figure 5). Significant differences in values and types of intermediates between photocatalytic and photolytic 
conversions of SFX after $2 \mathrm{~h}$ UV(A) irradiation were observed. Furthermore, the comparison between Figure $5 \mathrm{a}, \mathrm{b}$ revealed that the produced intermediates throughout the photocatalytic reaction were completely degraded or converted after $24 \mathrm{~h}$ UV(A) irradiation, while in the photolytic reaction, not only were the produced intermediates not removed after $24 \mathrm{~h} \mathrm{UV}(\mathrm{A})$ irradiation, but also some new ones were detected at the end of the reaction.

During the photolytic conversion of SFX upon UV(A) irradiation, the intermediate with the most intense signal $(\mathrm{m} / \mathrm{z}=317)$, was detected at $11.7 \mathrm{~min}$ retention time. This signal was increasingly produced from $15 \mathrm{~min}$ to $6 \mathrm{~h}$ irradiation and it remained stable until the end of the $24 \mathrm{~h} \mathrm{UV}(\mathrm{A})$ irradiation. Another signal at retention time of $15.8 \mathrm{~min}$, corresponding to a combination of $\mathrm{m} / \mathrm{z}=301$ and $\mathrm{m} / \mathrm{z}=318$ was detected from $30 \mathrm{~min}$ until $4 \mathrm{~h}$ irradiation. Moreover, some new peaks (mainly low intensity signals) corresponding to $\mathrm{m} / \mathrm{z}=333,303,269$, and 287 emerged along the UV(A) irradiation. However, during the photocatalytic reaction, other detected intermediates after $2 \mathrm{~h}$ irradiation corresponding to $\mathrm{m} / \mathrm{z}=321$ and 250 were completely removed after $24 \mathrm{~h} \mathrm{UV(A)}$ irradiation. The fact that, under photocatalytic conditions, much lower concentrations of intermediates were detected indicates that the photocatalytic process is superior in removal of the produced intermediates compared to the photolytic process. Analyzing these intermediates suggested different reaction pathways for photocatalytic and photolytic conversion of SFX over $24 \mathrm{~h}$ UV(A) irradiation.

Also upon irradiation with visible light, some differences between the photocatalytic and the photolytic reactions were observed. Therefore, the intermediates of the photocatalytic and the photolytic reactions of SFX after $2 \mathrm{~h}$ and $24 \mathrm{~h}$ of visible irradiation were analyzed and compared as well (Figure 6).

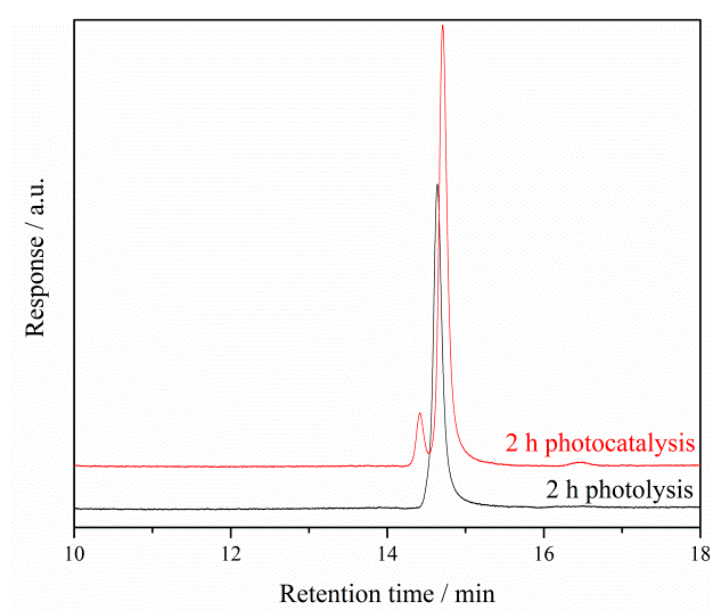

(a)

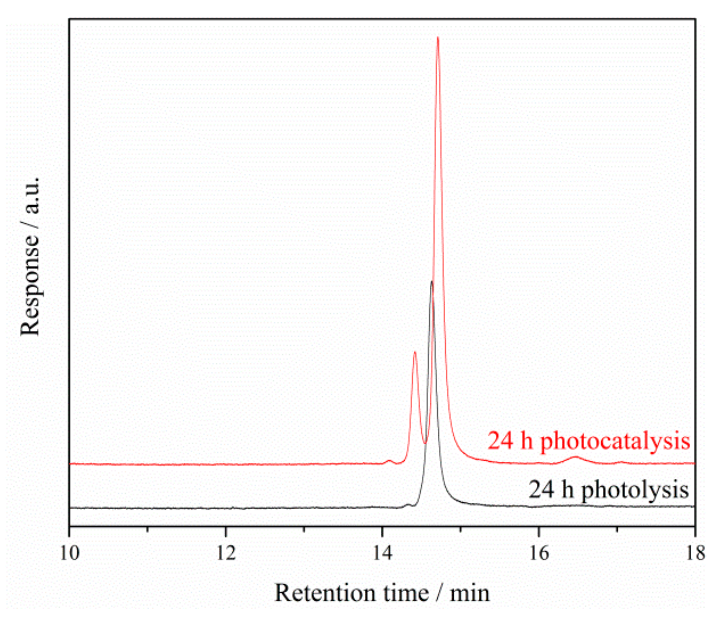

(b)

Figure 6. Chromatograms of SFX samples under both photocatalytic and photolytic conditions upon irradiation with visible light after: (a) $2 \mathrm{~h}$ and (b) $24 \mathrm{~h}$.

As observed in Figure 6, throughout the photocatalytic reaction upon visible light irradiation, no significant difference in the signal intensity of SFX was detected from $2 \mathrm{~h}$ to $24 \mathrm{~h}$ (only $7 \%$ decrease); revealing that this compound was highly stable throughout the reaction period. During this process, an evolving small signal at retention time of about $14.4 \mathrm{~min}$ (attached to the SFX signal) corresponding to $\mathrm{m} / \mathrm{z}$ value of 321 was observed. The intensity of this signal slightly increased over the $24 \mathrm{~h}$ visible light irradiation. Furthermore, throughout the photolytic experiments upon visible light irradiation, the signal intensity of SFX from $2 \mathrm{~h}$ to $24 \mathrm{~h}$ decreased up to $17 \%$, while no other intermediates were detected, confirming that the SFX was highly stable during visible light photolysis.

\subsection{Photocatalytic and Photolytic Conversion of Chlorpromazine under Anaerobic Conditions}

In addition, the photo-induced intermediates of photolytic and photocatalytic conversions of chlorpromazine under anaerobic conditions were evaluated. The obtained results are presented in 
Figure 7. It was observed that upon UV(A) irradiation, the rate of chlorpromazine conversion as well as production rates and types of the intermediates under anaerobic conditions were completely different from aerobic conditions. However, chlorpromazine was not converted under anaerobic conditions upon visible light irradiation both in presence and absence of K-7000 and, therefore, no intermediates were detected for those experimental runs.

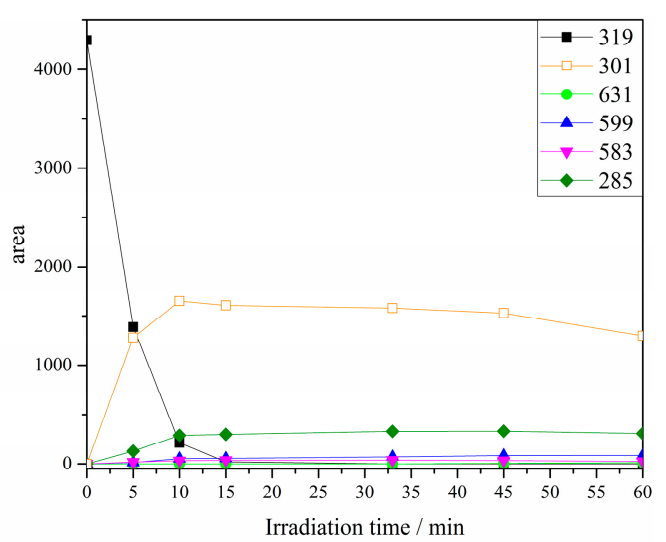

(a)

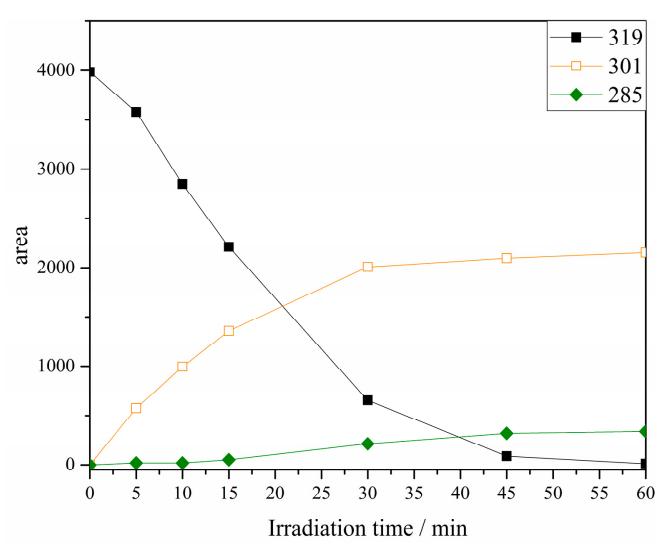

(b)

Figure 7. Conversion of chlorpromazine into its metabolites under anaerobic conditions: (a) photolysis upon UV(A) irradiation, (b) photocatalysis upon UV(A) irradiation with K-7000 as photocatalyst $\left(1 \mathrm{~g} \mathrm{~L}^{-1}\right)$.

A simple comparison between the aerobic and anaerobic photolysis of chlorpromazine upon $\mathrm{UV}(\mathrm{A})$ irradiation clearly reveals their different reaction pathways. The reaction products/intermediates of the aerobic UV(A) photolytic reaction were found to have $\mathrm{m} / \mathrm{z}$ values of 335, 301, and 317 (Figure 3c). However, throughout the anaerobic photolysis of chlorpromazine upon UV(A) irradiation (Figure 7a), no traces of SFX (m/z: 335) were found and other products/intermediates, with $\mathrm{m} / \mathrm{z}$ values of 301, 285, 631,599 , and 583 were detected. The compound with $\mathrm{m} / \mathrm{z}$ value of 285 is most likely promazine which has been also identified under anaerobic conditions by Davies et al. via comparing the retention factor with that of an authentic sample. They have shown that in an oxygen-free system, the photo-excited chlorpromazine undergoes a dechlorination step to form free radicals which then react with the solvent and produce promazine and other products [58]. Detection of the products with larges $\mathrm{m} / \mathrm{z}$ values of 631,599 , and 583 is an evidence of formation of different chlorpromazine dimers during this reaction. Similar observations were reported by Huang and Sands confirming that under anaerobic UV photolysis of chlorpromazine, polymerization and dimerization processes take place and that the free radical cations of chlorpromazine resulted from cleavage of chloride function from the structure promotes these processes [56].

On the other hand, in the presence of the photocatalyst upon anaerobic conditions (Figure $7 \mathrm{~b}$ ), the conversion of chlorpromazine slowed down but it still happened, while only two products with $\mathrm{m} / \mathrm{z}$ values of 301 and 285 were detected and no dimers or polymers were formed. In the photocatalytic system, the photocatalyst absorbs the main part of the incident photons. Consequently, the key step of the dimerization and polymerization process, namely, the formation of chlorpromazine free radicals will be limited.

Interestingly, during both anaerobic photolysis and photocatalysis of chlorpromazine, the products with $\mathrm{m} / \mathrm{z}$ values of 301 and 285 were found to be the most stable ones among all other intermediates. These masses most probably correspond to the chemical structures proposed in Figure 8, in which the chlorine in the chlorpromazine structure is replaced with an $\mathrm{OH}$ or hydrogen. 


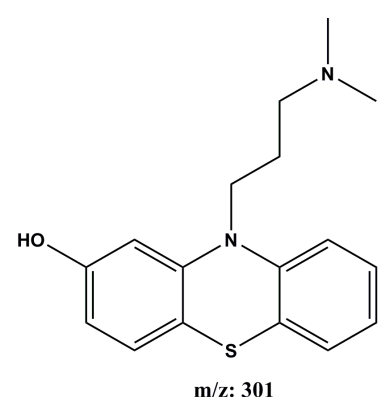

(a)

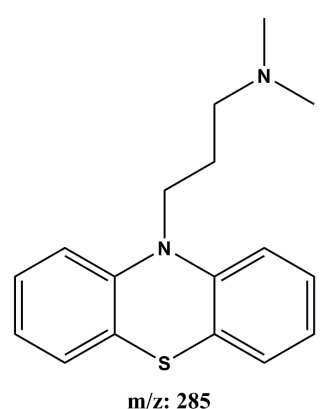

(b)

Figure 8. Possible structures of the two most stable products under anaerobic conditions.

During the photocatalytic reaction in the presence of oxygen, most of the photons are absorbed by the photocatalyst resulting into its excitation. In this case two reactions are likely to happen; either the photo-generated conduction band electrons react with the oxygen resulting into $\mathrm{O}_{2}{ }^{-\bullet}$ or they reduce the chlorpromazine and break the $\mathrm{C}-\mathrm{Cl}$ bond, leaving $\mathrm{Cl}^{-}$and the radical of chlorpromazine. The probability of the second path is rather low in the presence of oxygen as it is a highly strong electron scavenger. However, in oxygen-free conditions, the first reaction cannot occur, thus, chlorpromazine will be the only electron acceptor present in the system resulting in the dechlorination of this compound. Considering the possible structures of the two most stable products under anaerobic conditions (Figure 8), the $\mathrm{C}-\mathrm{Cl}$ bond in the structure of chlorpromazine was replaced with a $\mathrm{C}-\mathrm{OH}$ or a $\mathrm{C}-\mathrm{H}$ bond. To yield these products, the dechlorinated chlorpromazine radical requires reaction with ${ }^{\bullet} \mathrm{H}$ or ${ }^{\bullet} \mathrm{OH}$. These radicals are suggested to result from the reaction of the chlorpromazine radical with water. Although the reactions between organic radicals and water are usually quite unlikely, such reactions have been reported before under anaerobic conditions [59]. Therefore, detection of the products with $\mathrm{m} / \mathrm{z}$ values of 301 and 285 in the absence of oxygen proposes the possible reaction of electrons instead of hydroxyl radicals. It seems to be likely that these products are formed through the reduction reaction of chlorpromazine which is more expected to take place in the absence of oxygen.

\subsection{Participation of OH Radicals in the Degradation Pathway of Chlorpromazine}

To evaluate the role of hydroxyl radicals throughout the photocatalytic transformation or oxidation of chlorpromazine and formation of its intermediates or products, an analysis on the amount of produced hydroxyl radicals upon both UV(A) and visible light irradiation under aerobic conditions in the presence of K-7000 photocatalyst was performed. Hydroxyl radical is one of the major oxidants in photocatalytic processes. Throughout a photocatalytic reaction, the formation of hydroxyl radicals on the surface of the photocatalyst upon irradiation is correlated with photocatalytic conversion of the probe compound through these radicals generated from photoexcitation of the photocatalyst surface [60]. For this matter, terephthalic acid was applied as a probe molecule which is known to react specifically with $\mathrm{OH}$ radicals transforming into a fluorescent product, 2-hydroxyterephthalic acid. This reaction product is intensely fluorescent whereas terephthalic acid itself is non-fluorescent [61]. Irradiating the terephthalic acid suspension at $315 \mathrm{~nm}$ wavelength results in generation of a strong fluorescent signal with a maximum at around $425 \mathrm{~nm}$. The signal intensity which is directly detected and measured corresponds to the concentration of the product (2-hydroxyterephthalic acid) in the suspension. Thus, it is possible to identify the $\mathrm{OH}$ radical concentration in the suspension through this method [62].

Accordingly, a suspension of $0.4 \mathrm{mM}$ TA $(99 \%)$ and $1 \mathrm{mM} \mathrm{NaOH}$ with $1 \mathrm{~g} \mathrm{~L}^{-1}$ photocatalyst concentration was irradiated for $60 \mathrm{~min}$ with $\mathrm{UV}(\mathrm{A})$ and visible light. Figure 9 presents the amount of produced 2-hydroxyterephthalic acid from this suspension upon UV(A) irradiation vs. irradiation time. Upon visible light irradiation no formation of hydroxyl radicals was observed. 


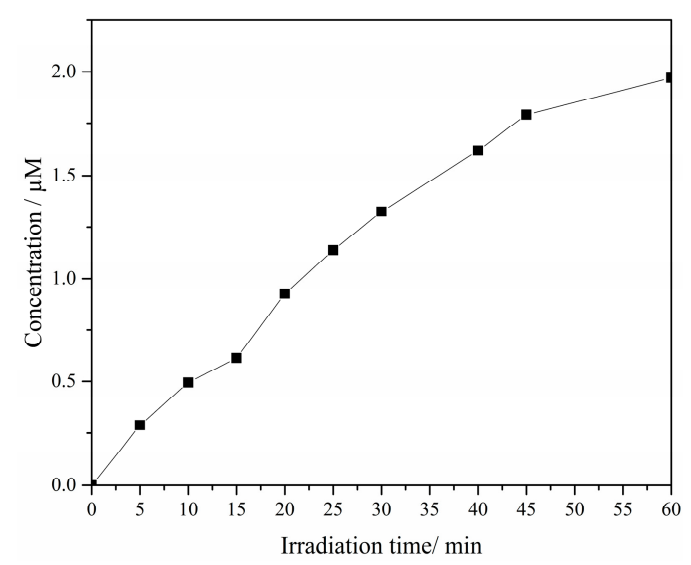

Figure 9. Amount of the produced 2-hydroxyterephthalic acid from the UV(A)-irradiated suspension of terephthalic acid and K-7000.

As can be seen, upon UV(A) irradiation at $365 \mathrm{~nm}$ wavelength, an increased production of 2-hydroxyterephthalic acid over the irradiation time was observed which was proportional to the amount of hydroxyl radicals. This revealed that hydroxyl radicals were produced at the surface of the photocatalyst. Wilde et al. have studied the degradation of different phenothiazines by hydroxyl radicals produced through a Fenton process. Based on their UHPLC-HRMS ${ }^{n}$ data, for the degradation of chlorpromazine by hydroxyl radicals, a dechlorination step leading to products with $\mathrm{m} / \mathrm{z}$ values of 301 and 285 was reported which is likely to result in a product with $\mathrm{m} / \mathrm{z}$ value of 317 , eventually after an extra hydroxylation step. Other transformation products with $\mathrm{m} / \mathrm{z}$ values of 335 and 351 were also proposed to be formed after one or two aromatic hydroxylation steps instead of S-oxidation in the chlorpromazine structure [44]. In the current study, similar products with $\mathrm{m} / \mathrm{z}$ values of 335,351 , and 317 were observed upon aerobic photocatalytic conversion of chlorpromazine. This indicates the degradation of chlorpromazine mainly by hydroxyl radicals produced upon UV(A) irradiation under aerobic conditions in the presence of K-7000 photocatalyst. However, the intermediates with $\mathrm{m} / \mathrm{z}$ values of 285 and 301 were not detected, most likely due to the quick transformation of chlorpromazine to the other products.

Nevertheless, upon visible light irradiation under aerobic conditions no formation of hydroxyl radicals was observed indicating that the conversion of chlorpromazine in the presence of K-7000 photocatalyst did not result from the reaction between a photocatalytically generated $\mathrm{OH}$ radical and the chlorpromazine molecule and that the contribution of $\mathrm{OH}$ radicals in conversion of chlorpromazine upon visible light irradiation is almost negligible. Therefore, the photocatalytic conversion of chlorpromazine upon visible light irradiation is most likely approached through a direct mechanism. This means that the photogenerated electrons attack the chlorpromazine molecule and produce a free radical which then reacts with water or molecular oxygen in the system and results in the detected products with $\mathrm{m} / \mathrm{z}$ values of 335,351 . Moreover, observation of these products upon visible light irradiation under aerobic conditions also confirms that in the absence of hydroxyl radicals, the dechlorination step does not take place.

Accordingly, the main detected intermediates in photocatalytic conversions of chlorpromazine under anaerobic and aerobic conditions upon both UV(A) and visible light irradiation are gathered and presented in Figure 10, proposing the reaction pathway for these procedures. 


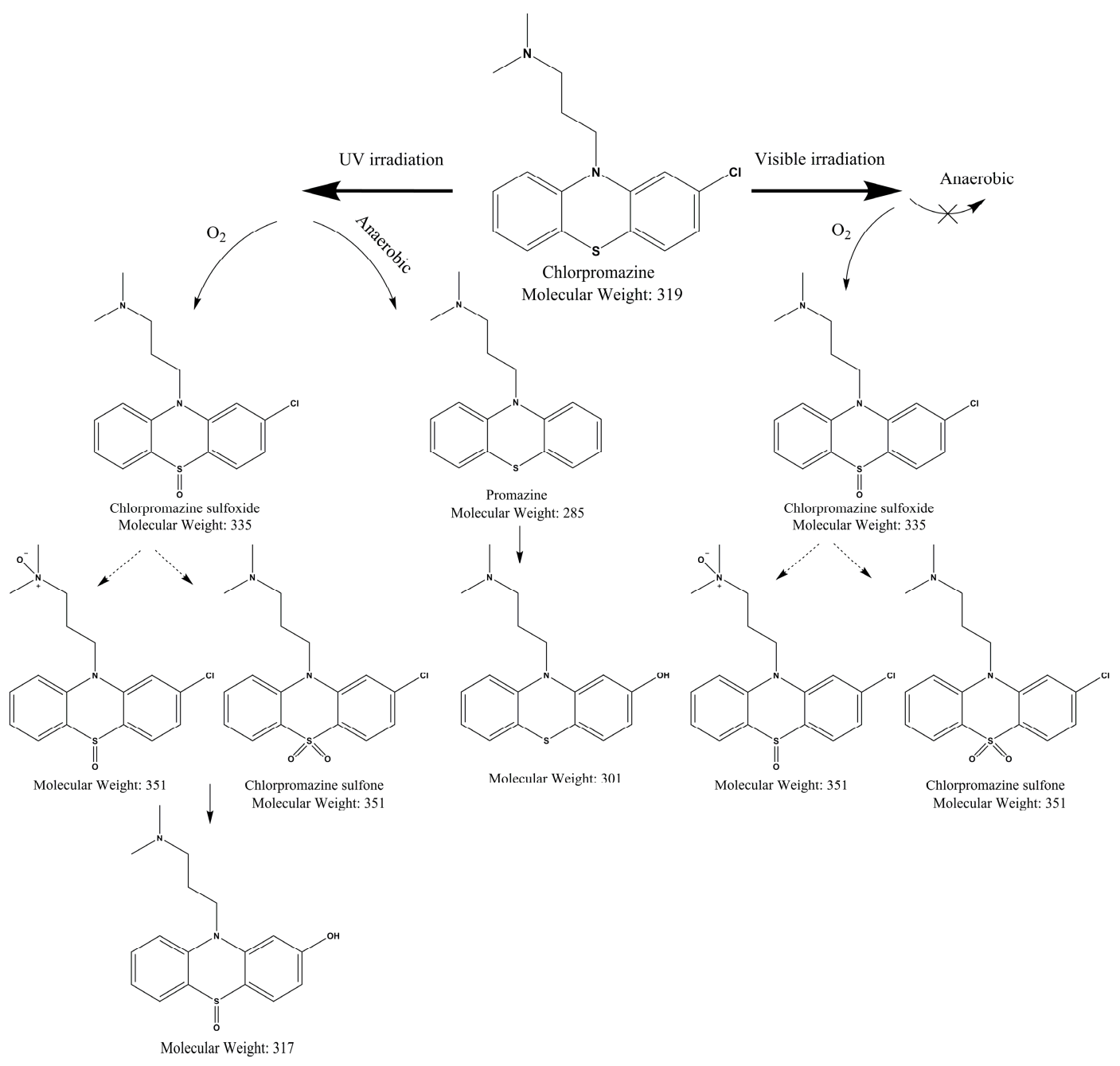

Figure 10. The proposed reaction pathway for photocatalytic conversion of chlorpromazine.

\section{Materials and Methods}

\subsection{Materials}

The commercial carbon-modified titanium dioxide powder (Kronos International, Inc., Leverkusen, NRW, Germany), KRONOClean 7000 (K-7000), was applied as the photocatalyst in this work. The commercial chlorpromazine sulfoxide (SFX) was purchased from LGC-Standards (Wesel, NRW, Germany). Acetonitrile (Rotisolv ${ }^{\circledR}$ HPLC Gradient) was purchased from Carl-Roth (Karlsruhe, BW, Germany). Chlorpromazine hydrochloride ( $\geq 98 \%)$, trifluoroacetic acid (spectroscopy Uvasol $\left.{ }^{\circledR}\right)$, and all other chemicals in the present study were purchased from Sigma-Aldrich (Merck, Darmstadt, HE, Germany) (if no additional notation is made). All the chemicals were used as purchased without further purification. Ultrapure water $(\geq 18.2 \mathrm{M} \Omega \mathrm{cm})$ was applied in all the experiments.

\subsection{Photocatalytic Procedure}

The photocatalytic experiments of chlorpromazine conversion using K-7000 as photocatalyst, as well as photolysis of chlorpromazine under both $U V(A)(365 \mathrm{~nm})$ and visible (455 nm) light irradiation were performed. These experiments were carried out in a closed cylindrical borosilicate photoreactor (diameter: $6 \mathrm{~cm}$, height: $3 \mathrm{~cm}$ ) covered in a shell made of a black polymer which was connected from the top to one of the monochromatic LED light sources emitting at $365 \mathrm{~nm}$ (Thorlabs, M365L2, $190 \mathrm{~mW}$, 
$700 \mathrm{~mA}$ ) or $455 \mathrm{~nm}$ (Thorlabs, M455L3, $900 \mathrm{~mW}, 1000 \mathrm{~mA}$ ) irradiation wavelengths. For each of the LED lamps the photon flux density, $\mathrm{N}\left(\mathrm{s}^{-1} \mathrm{~cm}^{-2}\right)$ was calculated through the following equation:

$$
\mathrm{N}=\int_{\lambda_{1}}^{\lambda_{2}} \frac{\mathrm{I}}{\mathrm{E}} \mathrm{d} \lambda
$$

The spectral irradiance, I $\left(\mathrm{mW} \mathrm{cm}^{-2} \mathrm{~nm}^{-1}\right)$ was measured by a SpectraRad ${ }^{\circledR}$ Xpress (B\&W Tek, Lübeck, SH, Germany)) spectral irradiance meter. E, the energy of a photon with wavelength $\lambda$ was calculated by the Planck-Einstein relation [63]. The calculated $N$ value was found to be $1.12 \times 10^{16} \mathrm{~s}^{-1} \mathrm{~cm}^{-2}$ for the UV(A) LED lamp (365 nm) and $7.47 \times 10^{16} \mathrm{~s}^{-1} \mathrm{~cm}^{-2}$ for the visible light LED lamp (455 nm). The UV/Vis spectrum of chlorpromazine was recorded employing a UV-visible Cary-100 spectrophotometer.

For each experimental run, an aqueous suspension containing $100 \mu \mathrm{M}$ chlorpromazine (or SFX) and $1 \mathrm{~g} \mathrm{~L}^{-1}$ photocatalyst was prepared. The reactor was filled with $60 \mathrm{~mL}$ of reaction suspension which was first stirred in the dark for $60 \mathrm{~min}$ to ensure the adsorption equilibrium. Clearly, for the photolytic experiments, the dark period was not required. Subsequently, the suspension was irradiated for $180 \mathrm{~min}$. In aerobic experiments the suspension was purged with oxygen and in anaerobic conditions the suspension was purged with argon throughout the reaction period. In the case of long-term experiments, the irradiation time was extended to $24 \mathrm{~h}$. At certain time intervals, samples were taken from the sampling point provided on the reactor, centrifuged, filtered (PVDF, $0.2 \mu \mathrm{m}$ pore size), and finally, the supernatant was obtained and analyzed through HPLC-MS analysis. The results of these experiments were reported as the conversion of the probe compound calculated from the ratio of its concentration at a desired reaction time to initial concentration of this compound after equilibrium $\left(\mathrm{C} / \mathrm{C}_{0, \mathrm{e}}\right)$.

\subsection{HPLC-MS Analysis}

The product distribution was determined by HPLC-UV-MS (ESI) using an Alliance 2795-HT HPLC (Waters, UK) coupled with a 1050 UV-detector (type 79853C, detection wavelength $=254 \mathrm{~nm}$, HP, USA) and an LCT Premier ESI mass spectrometer (Waters, UK). The chromatography was performed on an Eurospher II $\mathrm{C}_{18}$ HPLC column $(150 * 4$ mm, Eurospher II 100-5 C18A, Knauer, Germany) using water (A) and acetonitril (B), each containing $0.1 \%$ trifluoroacetic acid, at a flow rate of 600

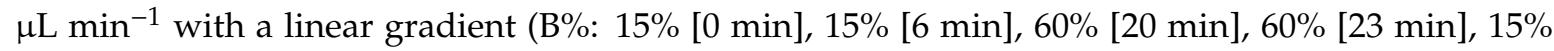
[26 min]; runtime $=35 \mathrm{~min}$ ). The following relevant MS settings were used: polarity $=\mathrm{ESI}+$; capillary voltage $=2700 \mathrm{~V}$; desolvation temperature $=350{ }^{\circ} \mathrm{C}$; desolvation gas flow $=650 \mathrm{~L} \mathrm{~h}^{-1}$ (nitrogen); source temperature $=100^{\circ} \mathrm{C}$; sample cone voltage $=30 \mathrm{~V}$.

\subsection{Determination of $\mathrm{OH}$ Radicals}

In order to detect the possible photocatalytic formation of hydroxyl radicals, the terephthalic acid (TA) test [33] was performed upon both UV(A) and visible light irradiation wavelengths. Accordingly, a calibration curve using different concentrations of 2-hydroxyterephthalic acid (97\%) was prepared. To measure the hydroxyl radical formation, a solution of $0.4 \mathrm{mM}$ TA $(99 \%)$ and $1 \mathrm{mM} \mathrm{NaOH}$ was prepared and the photocatalyst (K-7000) was added to reach a $1 \mathrm{~g} \mathrm{~L}^{-1}$ concentration in the suspension. This was followed by a 40 min ultrasonic dispersion step and the suspension was then left in the dark for $1 \mathrm{~h}$ under continuous stirring.

Afterwards, the suspension was divided into two parts which were irradiated separately with the same UV(A) and visible light sources used for the photocatalytic experiments. Accordingly, at desired time intervals, samples were taken from these suspensions, centrifuged, and analyzed via a Hitachi fluorescence spectrophotometer model F-700 recording the emission in the range of 400 to $600 \mathrm{~nm}$ (excitation wavelength $=315 \mathrm{~nm}$ ). 


\section{Conclusions}

The experimental results of this work revealed that the conversion rate of the probe compound, chlorpromazine, as well as type and production rates of the reaction intermediates varies using different irradiation wavelengths. Although chlorpromazine was converted directly upon UV(A) irradiation into its metabolites, for its conversion upon visible light irradiation, the presence of a visible-light active photocatalyst was necessary. Furthermore, observation of the products with $\mathrm{m} / \mathrm{z}$ values of 301 and 285 under anaerobic conditions suggested the reduction of chlorpromazine through electrons and not the hydroxyl radicals.

A persistent intermediate, namely, chlorpromazine sulfoxide (SFX) was the main reaction intermediate of visible-light photolytic and photocatalytic conversions of chlorpromazine under aerobic conditions. Although chlorpromazine was completely converted upon visible-light photocatalysis within the first $30 \mathrm{~min}$ of irradiation, this persistent intermediate, SFX, was highly stable over the $24 \mathrm{~h}$ of constant visible light irradiation even in the presence of K-7000 photocatalyst. This long-lasting compound was converted extremely slowly over a long-term heterogeneous photocatalytic process under UV(A) irradiation, however, the required irradiation time for complete removal of SFX was found to be at least 20 times longer compared to the removal of chlorpromazine at the same initial concentration. Nevertheless, the photocatalytic and photolytic conversions of SFX were found to have different reaction pathways. Moreover, throughout the photocatalytic pathway, the reaction intermediates or metabolites were successfully removed from the reaction medium indicating the superior ability of the photocatalytic process in the removal of the produced intermediates compared to the photolytic process.

Author Contributions: Conceptualization, A.A.; methodology, A.A.; validation, A.A.; formal analysis, A.A.; investigation, A.A. and G.D.; writing—original draft preparation, A.A. and G.D.; writing—review and editing, A.A. and R.D.; visualization, A.A.; supervision, D.B. and R.D.

Funding: This research received no external funding.

Acknowledgments: The financial support from the Deutscher Akademischer Austauschdienst (DAAD) and the Saint-Petersburg State University is gratefully acknowledged. The publication of this article was funded by the Open Access fund of Gottfried Wilhelm Leibniz Universität Hannover.

Conflicts of Interest: The authors declare no conflict of interest.

\section{References}

1. Radjenović, J.; Sirtori, C.; Petrović, M.; Barceló, D.; Malato, S. Solar photocatalytic degradation of persistent pharmaceuticals at pilot-scale: Kinetics and characterization of major intermediate products. Appl. Catal. B Environ. 2009, 89, 255-264. [CrossRef]

2. Fatta-Kassinos, D.; Vasquez, M.I.; Kümmerer, K. Transformation products of pharmaceuticals in surface waters and wastewater formed during photolysis and advanced oxidation processes - Degradation, elucidation of byproducts and assessment of their biological potency. Chemosphere 2011, 85, 693-709. [CrossRef] [PubMed]

3. Jones, O.A.H.; Voulvoulis, N.; Lester, J.N. Human pharmaceuticals in wastewater treatment processes. Crit. Rev. Environ. Sci. Technol. 2005, 35, 401-427. [CrossRef]

4. Taylor, D.; Senac, T. Human pharmaceutical products in the environment - The "problem" in perspective. Chemosphere 2014, 115, 95-99. [CrossRef] [PubMed]

5. Mirzaei, A.; Chen, Z.; Haghighat, F.; Yerushalmi, L. Removal of pharmaceuticals and endocrine disrupting compounds from water by zinc oxide-based photocatalytic degradation: A review. Sustain. Cities Soc. 2016, 27, 407-418. [CrossRef]

6. Zwiener, C.; Frimmel, F.H. Oxidative treatment of pharmaceuticals in water. Water Res. 2000, 34, 1881-1885. [CrossRef]

7. Luo, Y.; Guo, W.; Ngo, H.H.; Nghiem, L.D.; Hai, F.I.; Zhang, J.; Liang, S.; Wang, X.C. A review on the occurrence of micropollutants in the aquatic environment and their fate and removal during wastewater treatment. Sci. Total Environ. 2014, 473-474, 619-641. [CrossRef] [PubMed] 
8. Bolong, N.; Ismail, A.F.; Salim, M.R.; Matsuura, T. A review of the effects of emerging contaminants in wastewater and options for their removal. Desalination 2009, 238, 229-246. [CrossRef]

9. Bernabeu, A.; Vercher, R.F.; Santos-Juanes, L.; Simón, P.J.; Lardín, C.; Martínez, M.A.; Vicente, J.A.; González, R.; Llosá, C.; Arques, A.; et al. Solar photocatalysis as a tertiary treatment to remove emerging pollutants from wastewater treatment plant effluents. Catal. Today 2011, 161, 235-240. [CrossRef]

10. Ganiyu, S.O.; van Hullebusch, E.D.; Cretin, M.; Esposito, G.; Oturan, M.A. Coupling of membrane filtration and advanced oxidation processes for removal of pharmaceutical residues: A critical review. Sep. Purif. Technol. 2015, 156, 891-914. [CrossRef]

11. De Jesus Gaffney, V.; Almeida, C.M.M.; Rodrigues, A.; Ferreira, E.; Benoliel, M.J.; Cardoso, V.V. Occurrence of pharmaceuticals in a water supply system and related human health risk assessment. Water Res. 2015, 72, 199-208. [CrossRef] [PubMed]

12. Bollmann, A.F.; Seitz, W.; Prasse, C.; Lucke, T.; Schulz, W.; Ternes, T. Occurrence and fate of amisulpride, sulpiride, and lamotrigine in municipal wastewater treatment plants with biological treatment and ozonation. J. Hazard. Mater. 2016, 320, 204-215. [CrossRef] [PubMed]

13. Prieto-Rodriguez, L.; Miralles-Cuevas, S.; Oller, I.; Agüera, A.; Puma, G.L.; Malato, S. Treatment of emerging contaminants in wastewater treatment plants (WWTP) effluents by solar photocatalysis using low $\mathrm{TiO}_{2}$ concentrations. J. Hazard. Mater. 2012, 211-212, 131-137. [CrossRef] [PubMed]

14. Klavarioti, M.; Mantzavinos, D.; Kassinos, D. Removal of residual pharmaceuticals from aqueous systems by advanced oxidation processes. Environ. Int. 2009, 35, 402-417. [CrossRef] [PubMed]

15. Trawiński, J.; Skibiński, R. Studies on photodegradation process of psychotropic drugs: A review. Environ. Sci. Pollut. Res. 2017, 24, 1152-1199. [CrossRef]

16. Spasiano, D.; Marotta, R.; Malato, S.; Fernandez-Ibañez, P.; Di Somma, I. Solar photocatalysis: Materials, reactors, some commercial, and pre-industrialized applications. A comprehensive approach. Appl. Catal. B Environ. 2015, 170-171, 90-123. [CrossRef]

17. Robertson, P.K.J.; Bahnemann, D.W.; Robertson, J.M.C.; Wood, F. Photocatalytic detoxification of water and air. Environ. Photochem. Part II 2005, 2, 367-423.

18. Malato, S.; Fernández-Ibáñez, P.; Maldonado, M.I.; Blanco, J.; Gernjak, W. Decontamination and disinfection of water by solar photocatalysis: Recent overview and trends. Catal. Today 2009, 147, 1-59. [CrossRef]

19. Mills, A.; Hunte, S. Le An overview of semiconductor photocatalysis. J. Photochem. Photobiol. A Chem. 1997, 108, 1-35. [CrossRef]

20. Hoffmann, M.R.; Martin, S.T.; Choi, W.; Bahnemann, D.W. Environmental applications of semiconductor photocatalysis. Chem. Rev. 1995, 95, 69-96. [CrossRef]

21. Bahnemann, D. Photocatalytic water treatment: Solar energy applications. Sol. Energy 2004, 77, 445-459. [CrossRef]

22. Fagan, R.; McCormack, D.E.; Dionysiou, D.D.; Pillai, S.C. A review of solar and visible light active $\mathrm{TiO}_{2}$ photocatalysis for treating bacteria, cyanotoxins and contaminants of emerging concern. Mater. Sci. Semicond. Process. 2016, 42, 2-14. [CrossRef]

23. Xu, A.; Gao, Y.; Liu, H. The Preparation, Characterization, and their Photocatalytic Activities of Rare-Earth-Doped $\mathrm{TiO}_{2}$ Nanoparticles. J. Catal. 2002, 207, 151-157. [CrossRef]

24. Klosek, S.; Raftery, D. Visible Light Driven V-Doped $\mathrm{TiO}_{2}$ Photocatalyst and Its Photooxidation of Ethanol. J. Phys. Chem. B 2001, 105, 2815-2819. [CrossRef]

25. Lee, K.; Yoon, H.; Ahn, C.; Park, J.; Jeon, S. Strategies to improve the photocatalytic activity of $\mathrm{TiO}_{2}$ : 3D nanostructuring and heterostructuring with graphitic carbon nanomaterials. Nanoscale 2019, 11, 7025-7040. [CrossRef] [PubMed]

26. Cho, S.; Ahn, C.; Park, J.; Jeon, S. 3D nanostructured N-doped $\mathrm{TiO}_{2}$ photocatalysts with enhanced visible absorption. Nanoscale 2018, 10, 9747-9751. [CrossRef] [PubMed]

27. O'Regan, B.; Grätzel, M. A low-cost, high-efficiency solar cell based on dye-sensitized colloidal $\mathrm{TiO}_{2}$ films. Nature 1991, 353, 737-740. [CrossRef]

28. Freitag, M.; Teuscher, J.; Saygili, Y.; Zhang, X.; Giordano, F.; Liska, P.; Hua, J.; Zakeeruddin, S.M.; Moser, J.-E.; Grätzel, M.; et al. Dye-sensitized solar cells for efficient power generation under ambient lighting. Nat. Photonics 2017, 11, 372-378. [CrossRef]

29. Cho, Y.; Choi, W.; Lee, C.; Hyeon, T.; Lee, H. Visible Light-Induced Degradation of Carbon Tetrachloride on Dye-Sensitized $\mathrm{TiO}_{2}$. Environ. Sci. Technol. 2001, 35, 966-970. [CrossRef] 
30. Chowdhury, P.; Moreira, J.; Gomaa, H.; Ray, A.K. Visible-Solar-Light-Driven Photocatalytic Degradation of Phenol with Dye-Sensitized $\mathrm{TiO}_{2}$ : Parametric and Kinetic Study. Ind. Eng. Chem. Res. 2012, 51, 4523-4532. [CrossRef]

31. Li, X.; Shi, J.-L.; Hao, H.; Lang, X. Visible light-induced selective oxidation of alcohols with air by dye-sensitized $\mathrm{TiO}_{2}$ photocatalysis. Appl. Catal. B Environ. 2018, 232, 260-267. [CrossRef]

32. Lang, X.; Zhao, J.; Chen, X. Visible-Light-Induced Photoredox Catalysis of Dye-Sensitized Titanium Dioxide: Selective Aerobic Oxidation of Organic Sulfides. Angew. Chemie Int. Ed. 2016, 55, 4697-4700. [CrossRef]

33. Ehret, A.; Stuhl, L.; Spitler, M.T. Spectral Sensitization of $\mathrm{TiO}_{2}$ Nanocrystalline Electrodes with Aggregated Cyanine Dyes. J. Phys. Chem. B 2001, 105, 9960-9965. [CrossRef]

34. Tobaldi, D.M.; Seabra, M.P.; Otero-Irurueta, G.; de Miguel, Y.R.; Ball, R.J.; Singh, M.K.; Pullar, R.C.; Labrincha, J.A. Quantitative XRD characterisation and gas-phase photocatalytic activity testing for visible-light (indoor applications) of KRONOClean 7000®. RSC Adv. 2015, 5, 102911-102918. [CrossRef]

35. Ząbek, P.; Eberl, J.; Kisch, H. On the origin of visible light activity in carbon-modified titania. Photochem. Photobiol. Sci. 2009, 8, 264. [CrossRef]

36. Quesada-Cabrera, R.; Mills, A.; O'Rourke, C. Action spectra of $\mathrm{P} 25 \mathrm{TiO}_{2}$ and a visible light absorbing, carbon-modified titania in the photocatalytic degradation of stearic acid. Appl. Catal. B Environ. 2014, 150-151, 338-344. [CrossRef]

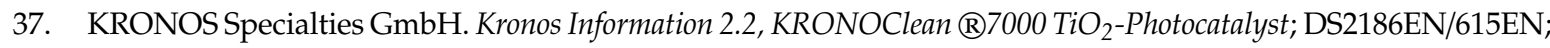
KRONOS Specialties GmbH: Leverkusen, NRW, Germany, 2015.

38. Herrmann, M.; Menz, J.; Gassmann, M.; Olsson, O.; Kümmerer, K. Experimental and in silico assessment of fate and effects of the antipsychotic drug quetiapine and its bio- and phototransformation products in aquatic environments. Environ. Pollut. 2016, 218, 66-76. [CrossRef]

39. Vardanyan, R.; Hruby, V. Antipsychotics. In Synthesis of Best-Seller Drugs; Elsevier: Amsterdam, The Netherlands, 2016; pp. 87-110. ISBN 978-0-12-411492-0.

40. Fourrier, A.; Gasquet, I.; Allicar, M.P.; Bouhassira, M.; Lépine, J.P.; Bégaud, B. Patterns of neuroleptic drug prescription: a national cross-sectional survey of a random sample of French psychiatrists. Br. J. Clin. Pharmacol. 2001, 49, 80-86. [CrossRef]

41. Boreen, A.L.; Arnold, W.A.; McNeill, K. Photodegradation of pharmaceuticals in the aquatic environment: A review. Aquat. Sci. Res. Across Bound. 2003, 65, 320-341. [CrossRef]

42. Andreozzi, R.; Raffaele, M.; Nicklas, P. Pharmaceuticals in STP effluents and their solar photodegradation in aquatic environment. Chemosphere 2003, 50, 1319-1330. [CrossRef]

43. Trautwein, C.; Kümmerer, K. Degradation of the tricyclic antipsychotic drug chlorpromazine under environmental conditions, identification of its main aquatic biotic and abiotic transformation products by LC-MS $^{\mathrm{n}}$ and their effects on environmental bacteria. J. Chromatogr. B Anal. Technol. Biomed. Life Sci. 2012, 889-890, 24-38. [CrossRef]

44. Wilde, M.L.; Schneider, M.; Kümmerer, K. Fenton process on single and mixture components of phenothiazine pharmaceuticals: Assessment of intermediaries, fate, and preliminary ecotoxicity. Sci. Total Environ. 2017, 583, 36-52. [CrossRef] [PubMed]

45. Buettner, G.R.; Motten, A.G.; Hall, R.D.; Chignell, C.F. Free radical production by chlorpromazine sulfoxide, an ESR spin-trapping and flash photolysis study. Photochem. Photobiol. 1986, 44, 5-10. [CrossRef] [PubMed]

46. López-Muñoz, F.; Alamo, C.; Cuenca, E.; Shen, W.W.; Clervoy, P.; Rubio, G. History of the discovery and clinical introduction of chlorpromazine. Ann. Clin. Psychiatry 2005, 17, 113-135. [CrossRef] [PubMed]

47. Nałecz-Jawecki, G.; Hajnas, A.; Sawicki, J. Photodegradation and phototoxicity of thioridazine and chlorpromazine evaluated with chemical analysis and aquatic organisms. Ecotoxicology 2008, 17, 13-20. [CrossRef] [PubMed]

48. Gocke, E. Review of the genotoxic properties of chlorpromazine and related phenothiazines. Mutat. Res. Genet. Toxicol. 1996, 366, 9-21. [CrossRef]

49. Bahnemann, D.; Asmus, K.-D.; Willson, R.L. Free radical induced one-electron oxidation of the phenothiazines chlorpromazine and promethazine. J. Chem. Soc. Perkin Trans. 1983, 2, 1661-1668. [CrossRef]

50. Ljunggren, B.; Moller, H. Phenothiazine phototoxicity: an experimental study on chlorpromazine and related tricyclic drugs. Acta Derm. Venereol. 1977, 57, 325-329.

51. Kochevar, I.E. Phototoxicity mechanisms: Chlorpromazine photosensitized damage to DNA and cell membranes. J. Invest. Dermatol. 1981, 77, 59-64. [CrossRef] 
52. Motten, A.G.; Buettner, G.R.; Chignell, C.F. Spectroscopic studies of cutaneous photosensitizing agents-VIII. A spin-trapping study of light induced free radicals from chlorpromazine and promazine. Photochem. Photobiol. 1985, 42, 9-15. [CrossRef]

53. Cheng, H.Y.; Sackett, P.H.; Mccreery, R.L. Kinetics of chlorpromazine cation radical decomposition in aqueous buffers. J. Am. Chem. Soc. 1978, 100, 962-967. [CrossRef]

54. Kigondu, E.M.; Njoroge, M.; Singh, K.; Njuguna, N.; Warner, D.F.; Chibale, K. Synthesis and synergistic antimycobacterial screening of chlorpromazine and its metabolites. Med. Chem. Commun. 2014, 5, 502-506. [CrossRef]

55. Boehme, C.L.; Strobel, H.W. High-performance liquid chromatographic methods for the analysis of haloperidol and chlorpromazine metabolism in vitro by purified cytochrome P450 isoforms. J. Chromatogr. B Biomed. Sci. Appl. 1998, 718, 259-266. [CrossRef]

56. Huang, C.L.; Sands, F.L. Effect of ultraviolet irradiation on chlorpromazine II. Anaerobic condition. J. Pharm. Sci. 1967, 56, 259-264. [CrossRef]

57. Khataee, A.R.; Fathinia, M.; Joo, S.W. Simultaneous monitoring of photocatalysis of three pharmaceuticals by immobilized $\mathrm{TiO}_{2}$ nanoparticles: Chemometric assessment, intermediates identification and ecotoxicological evaluation. Spectrochim. Acta Part A Mol. Biomol. Spectrosc. 2013, 112, 33-45. [CrossRef]

58. Davies, A.K.; Navaratnam, S.; Phillips, G.O. Photochemistry of chlorpromazine [2-chloro-N-(3dimethylaminopropyl)phenothiazine] in propan-2-ol solution. J. Chem. Soc. Perkin Trans. 2 1976, $25-29$. [CrossRef]

59. Hamid, S.; Ivanova, I.; Jeon, T.H.; Dillert, R.; Choi, W.; Bahnemann, D.W. Photocatalytic conversion of acetate into molecular hydrogen and hydrocarbons over $\mathrm{Pt} / \mathrm{TiO}_{2}: \mathrm{pH}$ dependent formation of Kolbe and Hofer-Moest products. J. Catal. 2017, 349, 128-135. [CrossRef]

60. Shafaei, A.; Nikazar, M.; Arami, M. Photocatalytic degradation of terephthalic acid using titania and zinc oxide photocatalysts: Comparative study. Desalination 2010, 252, 8-16. [CrossRef]

61. Barreto, J.C.; Smith, G.S.; Strobel, N.H.P.; McQuillin, P.A.; Miller, T.A. Terephthalic acid: A dosimeter for the detection of hydroxyl radicals in vitro. Life Sci. 1994, 56, PL89-PL96. [CrossRef]

62. Li, S.; Timoshkin, I.V.; Maclean, M.; Macgregor, S.J.; Wilson, M.P.; Given, M.J.; Wang, T.; Anderson, J.G. Fluorescence detection of hydroxyl radicals in water produced by atmospheric pulsed discharges. IEEE Trans. Dielectr. Electr. Insul. 2015, 22, 1856-1865. [CrossRef]

63. Arimi, A.; Megatif, L.; Granone, L.I.; Dillert, R. Visible-light photocatalytic activity of zinc ferrites. J. Photochem. Photobiol. A Chem. 2018, 366, 118-126. [CrossRef] 